\title{
Psychometric Evaluation of the Short Self-Regulation Questionnaire across Three European Countries
}

\author{
René Šebeňa, Olga Orosová \\ Faculty of Arts, P. J. Safarik University, Kosice, \\ Slovak Republic \\ Janina Petkeviciene \\ Faculty of Public Health, Medical Academy, \\ Lithuanian University of Health Sciences, \\ Lithuania \\ Ferdinand Salonna \\ Faculty of Physical Culture, Palacky University, \\ Olomouc, Czech Republic
}

\author{
Stefanie Helmer \\ Leibniz Institute for Prevention Research and \\ Epidemiology, Germany \\ Charité - Universitätsmedizin Berlin, Freie \\ Universität Berlin, Humboldt-Universität zu \\ Berlin, and Berlin Institute of Health, Institute \\ for Social Medicine, Epidemiology, and Health \\ Economics, Germany \\ Andrea Lukacs \\ Faculty of Health Care, University of Miskolc, \\ Hungary \\ Rafael Mikolajczyk \\ Martin Luther University Halle-Wittenberg, \\ Germany
}

\begin{abstract}
The aim of this study was to extend the psychometric evaluation of the Short Self-Regulation Questionnaire (SSRQ) by assessing the factor structure across three countries from Central and Eastern Europe. The sample included 1809 students from Slovakia, Lithuania and Hungary. Based on an initial confirmative factor analysis, a 2-factor structure by Neal and Carey (2005) was confirmed in the Lithuanian sample. Next, exploratory factor analyses were used on the Slovak and Hungarian subsamples separately. For both national subsamples, a very similar four factor solution was found, which was confirmed by confirmatory factor analyses on the rest of the data. Despite the reduced number of items, the abridged scale did not suffer in terms of its internal reliability and thus provides an adequate approximation of self-regulation levels as the entire scale or as the scale with the proposed 4-factor solution.
\end{abstract}

Key words: SSRQ, self-regulation, psychometric evaluation, university students

\section{Introduction}

From a social cognitive perspective, self-regulation is the ability of an individual to manage

Acknowledgements: This study was supported by APVV-0253-11 and APVV-15-0662 and the Grant Agency of the Ministry of Science, Research and Sport of the Slovak Republic and the Slovak Academy of Sciences VEGA 1/0713/15. Special thanks to Jozef Janovský, MSc. for his advice on the statistical analyses of data.

Correspondence concerning this paper should be addressed to René Šebeňa, Department of Psychology, Faculty of Arts, P. J. Safarik University in Kosice, Slovak Republic. E-mail: rene.sebena@upjs.sk

Received September 15, 2016 his own behavior through observation, evaluation, and consequation. It involves generating thoughts, feelings, and actions that are planned and adapted to the attainment of personal goals (Zimmerman, 2000). Self-regulation refers to the regular exercise of control over oneself in order to adapt (Zimmerman, 2000) and bring oneself in line with preferred standards (Carver \& Scheier, 1998; Vohs \& Baumeister, 2004). Selfregulation correlates with various aspects of life. For example two longitudinal, prospective studies of middle school students found that self-regulation helps students to study, complete homework, behave positively in the classroom, get better grades, and school attendance (Duckworth, Quinn, \& Tsukayama, 2012; 
Duckworth \& Seligman, 2005). In the context of health and interpersonal relationships, life goals have been found to be associated with higher levels of well-being and better mental health (Martos \& Kopp, 2012; Kasser \& Ahuvia, 2002; Sheldon, Klinesmith, Houser-Marko, Osbaldiston, \& Gunz, 2007). Hofer, Bush, and Kärtner (2011) found among a sample of university students that those with higher selfregulatory capabilities had higher levels of well-being. Other studies found self-regulation related to lower depression, anxiety and stress among university students (e.g., Park, Edmondson, \& Lee, 2012) or low psychopathological symptoms and better interpersonal relationships (Tangney, Baumeister, \& Boone, 2004).

Self-regulation skills also emerged as the predictors of avoiding problematic use of the internet and alcohol (Sebena, Orosova, \& Benka, 2013; Seay \& Kraut, 2007). Lower levels of self-regulation functions were found to be a risk factor for experiencing alcohol-related consequences and for reductions in alcohol use and consequences over time for heavier drinking college students (Hustad, Carey, Carey, \& Maisto, 2009).

Self-regulation can also be seen as relevant with respect to its theoretical implications. It is a key concept for understanding what the human self is and how it operates. Self-regulation is an important function of the human self, one that helps define self and is relevant with the self's executive function, which is related to self-control, control of the environment (has some relevance to self-knowledge and to interpersonal belonging), self-directed behavior or decision-making and choosing (Baumeister, Schmeichel, \& Vohs, 2007).

This study is based on Miller and Brown's (1991) theory, which proposed seven dimensions of self-regulation: 1) informational input, 2) self-monitoring current progress towards a personal goal, 3) motivation for change, 4) com- mitment to reaching the goal, 5) development of a plan to reach the personal goal, 6) work according to the plan and 7) re-evaluation of the plan. Miller and Brown's model implies that deficits in any one stage can lead to self-regulation difficulties and so individuals may have problems to regulate their behavior and to achieve the desired outcomes or goals.

In order to capture the dimensions of the mentioned Miller and Brown model (1991), the Self-Regulation Questionnaire (SRQ), a 63-item instrument was developed. After a psychometric evaluation of the SRQ, the 7 factors of the proposed self-regulation theory were not confirmed and the total sum score was recommended as a measure of general self-regulation skills (Brown, Miller, \& Lewandowski, 1999). Carey, Neal, and Collins (2004) extended the psychometric evaluation of the SRQ by evaluating its factor structure. However, the results did not confirm the 7-factor scale but rather a single factor. From this, 31 of the 63 items loaded significantly. As a result, a short form of the SRQ (SSRQ - Short Self-Regulation Questionnaire) consisting of these 31 items was produced (Carey, Neal, \& Collins, 2004). The next verification of the SSRQ found a 2-factor solution: impulse control and goal setting factors (Neal \& Carey, 2005).

To the best of our knowledge, no valid and reliable measurement tool for the self-regulation construct exists in the Slovak Republic. It was decided to choose a previously generated and tested general measure of self-regulation rather than a more specific one, so it could be used in various domains of human functioning. The aim of this study is to extend the psychometric evaluation of the SSRQ by assessing the factor structure across three countries from Central and Eastern Europe (Slovakia, Lithuania and Hungary).

The study specifically aimed to:

1) confirm the previous 7 -factor theoretical model by Miller and Brown (1991), the 1-factor 
model by Carey, Neal, and Collins (2004) and the 2-factor model by Neal and Carey (2005).

2) if confirmation failed, it aimed to provide a exploratory factor analysis across the three national samples.

\section{Method}

\section{Participants}

Data were used from the first wave of the Student Life Cohort in Europe (SLiCE), a multinational longitudinal study among first year university students from several European countries. This study is based on data collected in 2011. This study has been developed from the previous activities of the Cross-National Student Health Survey (El Ansari et al., 2007). The multinational cohort was planned for the whole period of university education. The collaborating universities were selected according to the personal contacts of the researchers. This analysis is based on the data from first year students in Hungary, Lithuania and the Slovak Republic, where over 500 participants were recruited from each country. In the three countries, nine universities took part in the study; four universities in Kaunas, Lithuania (Lithuanian University of Health Sciences, Kaunas University of Technology, Aleksandras Stulginskis and Vytautas Magnus University), two universities in Hungary (Eötvös Loránd University and the University of Miskolc) and three universities in
Kosice, Slovak Republic (P. J. Safarik University, the University of Veterinary Medicine, and the Technical University).

In each location, students were asked to complete self-administered online questionnaires. The strategies of recruiting respondents differed at each place because of the structural differences in the participating countries. The universities in Lithuania and the Slovak Republic provided access to the e-mails of all enrolled first year students. The project was introduced to students during their lectures and seminars and an invitation e-mail to participate was subsequently sent out. The Hungarian students were informed using university newsletters and other formal as well as informal methods. Following this, they registered on the SLiCE website and filled in the form. In total, the sample included 1809 students. The overall response rate was $22.69 \%$ (20.03\% in Slovakia, $23.05 \%$ in Lithuania, and $25 \%$ in Hungary) when comparing respondents to all enrolled university students in the given year at the respective universities. Generally, the universities included in this study represented biomedical, social, physical, and technical sciences.

\section{Characteristics of the Sample}

The mean age of the students was 20.15 years $(S D=3.38)$. The description of the samples from the different countries in terms of sex and age are shown in Table 1.

Table 1 Description of the sample by country

\begin{tabular}{lcccc}
\hline & $\begin{array}{c}\text { Slovakia } \\
\mathrm{N}=649\end{array}$ & $\begin{array}{c}\text { Lithuania } \\
\mathrm{N}=582\end{array}$ & $\begin{array}{c}\text { Hungary } \\
\mathrm{N}=578\end{array}$ & p-value \\
\hline Sex & & & & $.034^{*}$ \\
Female [\%] & 73.4 & 70.3 & 75.4 & \\
Male [\%] & 26.6 & 29.7 & 24.6 & \\
Age [mean (SD)] & $19.61(3.64)$ & $20.00(2.83)$ & $20.84(3.64)$ & $<.001$ \\
\hline
\end{tabular}

\footnotetext{
* Chi-square for comparison of sex proportionality between the three countries
} 
Student participation in the study was voluntary and anonymous. Students were informed that by completing the questionnaire they were providing their informed consent to participate. They were also informed that they could terminate their participation at any point while filling out the questionnaire. No incentives were provided. Permission to conduct the study was granted by the ethical commissions of the participating institutions. Initially, the questionnaire was compiled in English and subsequently translated into the local languages using two independent forward translations for each language. The research team reviewed any cases of disagreement and the authors familiar with the respective languages, usually native speakers, made the final decisions.

\section{Measures}

The measures used in this study were part of a multi-topical questionnaire assessing health and health behaviors among university students.

\section{Demographic Variables}

Students' sex and age were based on individuals' self-reports in the survey.

The Short Self-Regulation Questionnaire. The SSRQ is a 31-item scale that was designed to assess self-regulation skills. Items are scored on a 5-point scale from 1 - strongly disagree to 5 - strongly agree. A previous study by Neal and Carey (2005) indicates that the SSRQ has two distinct factors; an impulse control and a goal-setting factor. Questions on the impulse control factor include for example: "It's hard for me to notice when I've had enough (alcohol, food, sweets)," or "I am able to resist temptation." Questions on the goal setting factor include for example: "Once I have a goal, I can usually plan how to reach it" or "I am able to accomplish goals I set for myself".

\section{Statistical Analysis}

Two methods were used to assess the factor structure of the SSRQ. Principal component analysis was used to identify the factors in the whole sample and Structural Equation Modeling was used to further confirm the results across the countries.

Firstly, a confirmatory analysis approach was employed to test the factor structure of the three competing models. Secondly, exploratory factor analyses were conducted. Principal component analysis with a direct oblique rotation (Oblimin) and a covariance matrix as the input for the $2 / 3$ national subsamples separately were used. The Goodness of Fit Index (GFI) was computed, which showed how closely the model replicated the observed covariance matrix. In order to examine the results of the factor analysis further, an analysis of the individual items was conducted to assess the reliability and the convergent properties of the reduced SSRQ subscales. Then, we tested whether each item was individually correlated with the sum of the items in the same factor (item-test correlation) and the aggregate of the remaining items in that subscale (item-rest correlation). Finally, the internal consistency (Cronbach's Alpha) was computed for each factor, and for each factor minus one item in order to determine whether dropping an item would increase the overall internal consistency in a meaningful fashion.

To verify and confirm the factor structure of the model, Confirmatory Factor Analyses (CFA) were used. In order to define the good fit, several fit indices were applied. A satisfactory degree of fit requires the comparative fit index (CFI) to be close to 0.95 , and the model should be rejected when these indices are below 0.90 (Brown, 2006). The next fit index was the root mean squared error of approximation (RMSEA). A RMSEA below 0.05 indicates an excellent fit, a value around 0.08 indicates an adequate fit, 
and a value above 0.10 indicates a poor fit.

The PCLOSE measure, which goes with the RMSEA and provides the probability of a hypothesis test that the RMSEA is no greater than 0.05 , should be above 0.05 (Byrne, 2010).

The data analysis was performed using the statistical program PASW for Windows, version 18.0 and Amos 16.

\section{Results}

\section{Confirmatory Factor Analyses of Previous Models}

First of all, given that previous studies have tested the factor structure of the SSRQ, three competing models using the confirmatory analysis approach were initially tested on data that had no missing values. Based on the theorized model (Brown, Miller, \& Lewandowski, 1998), the 7-factor solution (Receiving, Evalu- ating, Triggering, Searching, Formulating, Implementing, Assessing) was tested on each national sample. However, this initial model, did not fit the data well in each selected country (see Table 2).

The results of Carey, Neal, and Collins (2004) revealed a 1-factor model on which all 31 items was loaded. However, testing the single factor model on each national sample did not provide an adequate fit to the data either (Table 3 ). The modification indices were examined within each factor structure model, which indicated that a number of substantial changes would need to be made in order to achieve a good fitting model. After that it was decided to test the bi-factorial structure by Neal and Carey (2005), considering the Impulse control factor and Goal setting factor. Neither of these factor structures fitted the data well for the Slovak and Hungarian national samples (see Table 4). However, for the Lithuanian sample, the modification indices in-

Table 2 CFA of the 7-factor theorized model by Brown, Miller and Lewandowski (1998)

\begin{tabular}{lcccccc}
\hline & $N$ & $\chi^{2}(p)$ & $G F I$ & $C F I$ & RMSEA & PCLOSE \\
\hline Slovak Republic & 649 & $2537(\mathrm{p}<.001)$ & .764 & .664 & .086 & $<.001$ \\
Hungary & 578 & $3433(\mathrm{p}<.001)$ & .689 & .646 & .109 & $<.001$ \\
Lithuania & 582 & $2291(\mathrm{p}<.001)$ & .763 & .720 & .086 & $<.001$ \\
\hline
\end{tabular}

Table 3 CFA of the one-factor model by Carey, Neal, \& Collins (2004)

\begin{tabular}{lcccccc}
\hline & $N$ & $\chi^{2}(p)$ & GFI & CFI & RMSEA & PCLOSE \\
\hline Slovak Republic & 649 & $1566(\mathrm{p}<.001)$ & .784 & .701 & .085 & $<.001$ \\
Hungary & 578 & $2313(\mathrm{p}<.001)$ & .746 & .740 & .092 & $<.001$ \\
Lithuania & 582 & $2007(\mathrm{p}<.001)$ & .788 & .746 & .084 & $<.001$ \\
\hline
\end{tabular}

Table 4 CFA of the two-factor model by Neal and Carey (2005)

\begin{tabular}{lcccccc}
\hline & $N$ & $\chi^{2}(p)$ & GFI & CFI & RMSEA & PCLOSE \\
\hline Slovak Republic & 649 & $1192(\mathrm{p}<.001)$ & .835 & .732 & .091 & $<.001$ \\
Hungary & 578 & $1126(\mathrm{p}<.001)$ & .824 & .740 & .093 & $<.001$ \\
Lithuania & 582 & $397(\mathrm{p}<.001)$ & .927 & .93 & .05 & .062 \\
\hline
\end{tabular}


dicated that three covariances between the errors of indicators within the same factor would need to be added in order to improve the model's fit. Two items ("I have trouble following through with things once I've made up my mind to do something." (Impulse Control) and "When I'm trying to change something, I pay a lot of attention to how I'm doing." (Goal Setting)) were removed because of a low factor loading. After this change, the goodness of fit for the Lithuanian sample was $\chi^{2}=397$ (141 df, $\left.p \leq .001\right)$, $\chi^{2} / \mathrm{df}=2.82, \mathrm{SRMR}=0.05, \mathrm{CFI}=0.93$, RMSEA $=$ 0.05 , PCLOSE $=0.06$. In terms of reliability, Cronbach's Alpha for the total score was $\alpha=87$, $\alpha=.80$ in the Goal setting and $\alpha=.81$ in Impulse control dimensions. This factor structure was accepted for the Lithuanian sample.

As the next step it was decided for the Slovak Republic and Hungarian national samples to move towards an exploratory factor analysis approach on the SSRQ items.

\section{Exploratory Factor Analyses}

A principal component exploratory analysis was conducted on $2 / 3$ randomly chosen separate Slovak and Hungarian subsamples. For both subsamples, four factors were revealed with eigenvalues of $6.3,2.1,1.6$ and 1.5 that cumulatively explained $50.1 \%$ of the total variance for the subsample from Slovakia and with eigenvalues of $8.7,1.8,1.4$ and 1.3 that cumulatively explained $55.2 \%$ of the total variance for the Hungarian subsample. Parallel analysis verified that the eigenvalues of the four factors of each national subsamples were greater than what was expected by chance, given the number of items and sample size. The 4-factor solution was rotated (Direct Oblimin) to improve its interpretability; 23 items were loaded onto the rotated factors at .435 or higher for the Slovak Republic and 24 items were loaded onto the rotated factors at .573 or higher for the Hungarian subsample. The KMO-measure of sampling adequacy was .88 for the Slovak and .912 for the Hungarian subsample. The Bartlett's test of sphericity was significant $(p<.001)$ across both national samples, supporting the factorability of the data. For the Slovak subsample, from the SSRQ-31 items, 23 items were classified as single-loading (loading $>.4$ on one factor and $<.2$ on the other), 8 were classified as crossloading items (loading $>.4$ on one factor and $>$ .2 on the other) or non-loading items.

7 items loaded significantly onto the first factor (self-discipline), 5 loaded significantly onto the second factor (goal-setting), 4 onto the third factor (learning from mistakes) and 7 loaded significantly onto the fourth factor (impulse control).

The study found very similar results for the factor structure for the Hungarian subsample, where 24 items were classified as single-loading and 7 as cross-loading or non-loading items. 8 items loaded significantly onto the first factor (self-discipline): "If I wanted to change, I am confident that I could do it." 5 loaded significantly onto the second factor (goal-setting): "I set goals for myself and keep track of my progress." 4 onto the third factor (learning from mistakes): "I usually only have to make a mistake one time in order to learn from it." 7 loaded significantly onto the fourth factor (impulse control): "Often I don't notice what I'm doing until someone calls it to my attention." The results of the exploratory factor analysis for both national subsamples are provided in Table 5.

\section{Item Analyses, Reliability Analyses}

For the item analyses to assess the reliability and convergent properties of the reduced SSRQ subscales, the study tested items belonging to each factor separately. Firstly, the items that had negative factor loadings were reversed to maintain consistency in the analyses.

In the Slovak subsample for factor 1, the itemtest correlations ranged from .64 to .77 , item- 


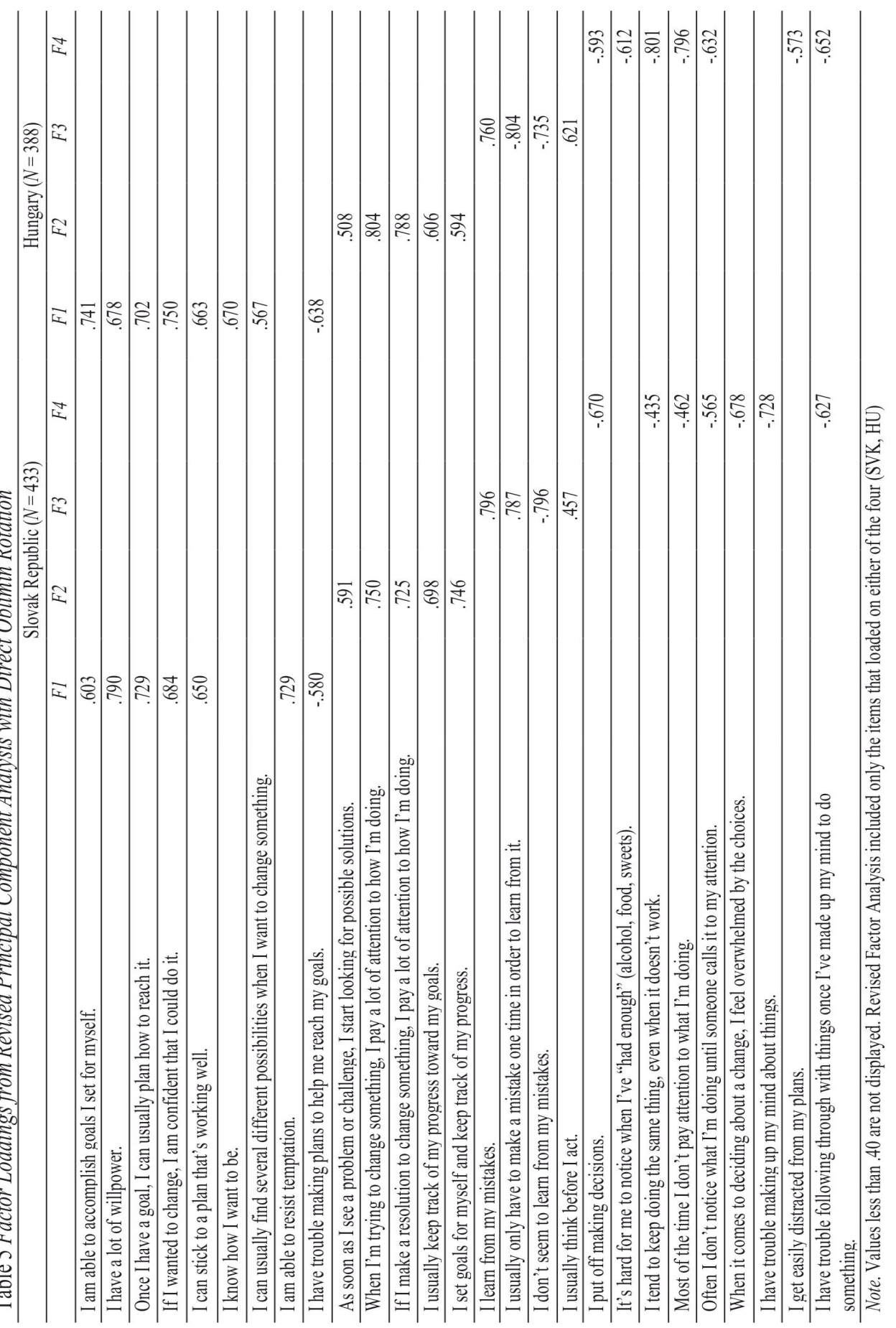


rest correlations ranged from .63 to .75, (overall alpha $=.76)$. For the second factor, item-test correlations ranged from .65 to .77 , item-rest correlations ranged from .62 to .74 , (overall alpha $=.79)$. For the third factor, item-test correlations ranged from .76 to .81, item-rest correlations ranged from .73 to .79 , (overall alpha $=$ .69). For the fourth factor, item-test correlations ranged from .56 to .70 , item-rest correlations ranged from .53 to .67 , (overall alpha $=.73$ ).

In the Hungarian subsample for factor 1 , the item-test correlations ranged from .64 to .77, item-rest correlations ranged from .61, to .75, (overall alpha $=.84)$. For the second factor, itemtest correlations ranged from .69 to .81 , itemrest correlations ranged from .65 to .78 , (overall alpha $=.81)$. For the third factor, item-test correlations ranged from .64 to .86 , item-rest correlations ranged from .60 to .83 , (overall alpha $=$ .77). For the fourth factor, item-test correlations ranged from .62 to .75 , item-rest correlations ranged from .60 to .72 , (overall alpha $=.81$ ).

The total internal consistency was also acceptable for the Slovak Republic (Cronbach's Alpha $=0.87$ (23 items) ) and Hungary, (Cronbach's Alpha = 0.92 (24 items)).

The correlation between the full 31-SSRQ version and the shortened version was .99 among both national subsamples.

\section{Confirmatory Factor Analyses of SSRQ by Structural Equation Modeling}

To verify the factor structure of the models from two countries, structural equation modeling was used. The analyses were made on the final $1 / 3$ of the data, which were not used in the exploratory factor analyses. The model fit was evaluated in terms of chi-square, standardized root mean square residuals (SRMR), and various goodness of fit indices.

First, we had a look at the factor structure of the Slovak Republic model. The modification indices indicated that adding three covariance between the errors of indicators within the same factor would need to be made in order to improve the model's fit. After this change, the goodness of fit for the model was $\chi^{2}=338.97$ (199 df, $p \leq .001), \chi^{2} / \mathrm{df}=1.70, \mathrm{SRMR}=0.05, \mathrm{CFI}$ $=0.91, \mathrm{RMSEA}=0.05, \mathrm{PCLOSE}=0.22$. The Hungarian model, derived from the exploratory factor analyses, showed very similar factor structure to the one derived from the Slovak Republic subsample. The modification indices indicated that two covariances would need to be added between the errors of indicators in order to improve the model's fit. After this change, the goodness of fit for the model was $\chi^{2}=292.61$ $(144 \mathrm{df}, p \leq .001), \chi^{2} / \mathrm{df}=2.03, \mathrm{SRMR}=0.05$, $\mathrm{CFI}=0.92, \mathrm{RMSEA}=0.05, \mathrm{PCLOSE}=0.12$. Although the $\chi^{2}$ was significant in both models here, other indexes showed that the model still fitted very well. Thus, it is possible to say that both models describe the data very well. The reason for this undesirable $\chi^{2}$ significance is the large sample size.

\section{Discussion and Conclusion}

The aim of this study was to provide a psychometric evaluation of the SSRQ -31 (Neal \& Carey, 2005) based on a university student sample from Slovakia, Lithuania and Hungary.

\section{Exploratory Factor Analyses}

Firstly, it was attempted to confirm the factor structure of the 7-factor theoretical model by Miller and Brown (1991) as well as the 1- and 2factor model (Carey, Neal, \& Collins, 2004; Neal \& Carey, 2005).

The results have supported the findings from other studies, namely, that the SSRQ does not follow the steps in the self-regulation theory as described by Miller and Brown (1991). Regarding the Slovak and Hungarian data, the study also failed to confirm the structure of the other two models (Carey, Neal, \& Collins, 2004; Neal 
\& Carey, 2005); none of them provided an adequate fit to the data in either country. However, we confirmed the 2-factor - impulse control and goal setting factors model by Neal and Carey (2005) in the Lithuanian sample. This twofactor model was also demonstrated in Portugal by Dias and Garcia del Castillo (2014).

For the Slovak and Hungarian data, it was decided to move towards an exploratory factor analysis, which showed that the best fitting model for both national datasets was the 4-factor model in comparison to the alternative models. The factor structure was similar in both national subsamples and from all 31 items, the final Slovak and Hungarian models revealed 20 items in common for both models.

The first two factors are made up of positively connoted items that are very similar to Neal and Carey's (2005) goal setting factor and seems to be very important in accomplishing the planned goals. This first factor was labeled in this study as Self-discipline. It contains items related to one's self-confidence, self-discipline and willpower to reach the goals: ("If I wanted to change, I am confident that I could do it.").

The second factor (Goal setting) consists of five items related to the ability to plan, set and keep track of a person's progress towards goal attainment. In both national samples, this factor contains the same 5 items, and all of them were part of Neal and Carey's (2005) goal setting factor (e.g., "I set goals for myself and keep track of my progress.").

The last two factors in both national samples are made up of 11 items that were part of Neal and Carey's (2005) impulse control factor. In the context of self-regulation, it is the ability to resist temptation, urges or impulses that may disrupt the goal directed behavior.

The third factor is labeled as Learning from mistakes and consists in both samples of four items related to learning from previous mistakes ("I usually only have to make a mistake one time in order to learn from it.").
The last factor (Impulse control) contains seven items that represent the awareness of a person's own thoughts and actions. All these items are negatively formulated with the aim of identifying one's automatic or mindful actions ("Most of the time I don't pay attention to what I'm doing.").

\section{Verification of Slovak and Hungarian Fac- tor Structure Model of SSRQ by Structural Equation Modeling}

In the next step, the study tried to verify the Slovak and the Hungarian factor structure models by Structural Equation Modeling (SEM). In the analyses, only the items that loaded on the four factors were included. It can be concluded that the 4-factor solution showed a good fit in the structural equation modeling in both national samples.

For all national samples we tested, it can be concluded that the validation of the SSRQ led to a satisfactory factor structure in all the national samples. The Goal Orientation and Impulse control factors seem to be the core of the SSRQ and self-regulation capacity and have also been confirmed in other studies (Neal \& Carey, 2005; Dias \& Garcia del Castillo, 2014).

Despite the limited number of items, the abridged scales did not suffer in its internal reliability, the correlation between the full 31-SSRQ version and the shortened versions showed a strong positive correlation and thus provides an adequate approximation of self-regulation levels as the entire scale or as the scale with the proposed 2 (Lithuania) or 4 factor solutions (Slovak Republic and Hungary).

It is believed that this shortened measure could provide valuable information about a person's self-regulation level. However, given the slightly differential results obtained in this study, it is recommended that there be a further examination of these factor structures as well as an assessment of the divergent and convergent validity. Its 
structure needs to be confirmed by other populations in order to make conclusive statements.

\section{Possible Implementations}

The potential usage of the SSRQ appears to be strong. The measure of general self-regulation capacity may be predictive of a wide range of behaviors. Self-regulation refers to the global process used to achieve goals. Thus, this measure could be used in predicting goal directed behaviors such as academic achievement, gambling, financial difficulties and behavior change process. In the future, we would like to evaluate this measure of self-regulation in relation to alcohol consumption and alcohol related problems.

\section{References}

Baumeister, R. F., Heatherton, T. F., \& Tice, D. M (1994). Losing control: How and why people fail at self-regulation. San Diego, CA: Academic Press.

Baumeister, R. F., Schmeichel, B. J., \& Vohs, K. D. (2007). Self-regulation and the executive function: The self as controlling agent. In A. W. Kruglanski \& E. T. Higgins (Eds.), Social psychology: Handbook of basic principles (2nd ed., pp. 516-539). New York: Guilford Press.

Brown, J. M. (1998). Self-regulation and the addictive behaviors. In W. R. Miller \& N. Heather (Eds.), Treating addictive behaviors (pp. 61-73.). New York: Plenum Press.

Brown, J. M., Miller, W. R., \& Lawendowski, L. A. (1999). The self-regulation questionnaire. In $\mathrm{L}$. VandeCreek \& T. L. Jackson (Eds.), Innovations in clinical practice: A source book (pp. 281-292). Sarasota, FL: Professional Resource Exchange.

Byrne, B. M. (2010). Structural equation modeling with AMOS: Basic concepts, applications, and programming. New York: Routledge.

Carey, K. B., Neal, D. J., \& Collins, S. E. (2004). A psychometric analysis of the self-regulation questionnaire. Addictive Behaviors, 29, 253-260.

Carver, C. S., \& Scheier, M. F. (1998). On the selfregulation of behavior. New York: Cambridge University Press.

Chen, F. F. (2007). Sensitivity of goodness of fit indexes to lack of measurement invariance. Structural Equation Modeling, 14(3), 464-504.
Duckworth, A. L., \& Seligman, M. E. P. (2005). Selfdiscipline outdoes IQ in predicting academic performance of adolescents. Psychological Science, 16, 939-944.

Duckworth, A. L., Quinn, P. D., \& Tsukayama, E. (2012). What no child left behind leaves behind: The roles of IQ and self-control in predicting standardized achievement test scores and report card grades. Journal of Educational Psychology, 104, 439-451.

El Ansari, W., Maxwell, A. E., Mikolajczyk, R. T., Stock, C., Naydenova, V., \& Kramer, A. (2007). Promoting public health: Benefits and challenges of a Europeanwide research consortium on student health. Central European Journal of Public Health, $15,58-65$.

Hofer, J., Busch, H., \& Kärtner, J. (2011). Self-regulation and well-being: The influence of identity and motives. European Journal of Personality, 25, 211224.

Hustad, J. T. P., Carey, K. B., Carey, M. P., \& Maisto, S. A. (2009). Self-regulation, alcohol consumption, and consequences in college student heavy drinkers: A simultaneous latent growth analysis. Journal of Studies on Alcohol and Drugs, 70(3), 373-382.

Cheung, G. W., \& Rensvold, R. B. (2002). Evaluating goodness-of-fit indexes for testing MI. Structural Equation Modeling, 9, 235-55.

Kanfer, F. H. (1970). Self-regulation: Research, issues, and speculation. In C. Neuringer \& J. L. Michael (Eds.), Behavior modification in clinical psychology (pp. 178-220). New York: Appleton-CenturyCrofts.

Kasser, T., \& Ahuvia, A. (2002). Materialistic values and well-being in business students. European Journal of Social Psychology, 32, 137-146.

Martos, T., \& Kopp, M. S. (2012). Life goals and wellbeing: Does financial status matter? Evidence from a representative Hungarian sample. Social Indicators Research, 105(3), 561-568.

Miller, W. R., \& Brown, J. M. (1991). Self-regulation as a conceptual basis for the prevention and treatment of addictive behaviors. In N. Heather, W. R. Miller, \& J. Greely (Eds.), Self-control and the addictive behaviours (pp. 3-79). Sydney: Maxwell Macmillan.

Neal, D. J., \& Carey, K. B. (2005). A follow-up psychometric analysis of the self-regulation questionnaire. Psychology of Addictive Behaviors, 14, 414422.

Park, C. L., Edmondson, D., \& Lee, J. (2012). Development of self-regulation abilities as predictors of psychological adjustment across the first year of college. Journal of Adult Development, 19(1), 4049. 
Seay, A. F., \& Kraut, R. E. (2007). Project massive: Self-regulation and problematic use of online gaming. In CHI 2007: Proceedings of the ACM conference on human factors in computing systems (pp. 829-838). New York: ACM Press.

Sebena, R., Orosova, O., \& Benka, J. (2013). Are selfregulation and depressive symptoms predictors of problematic Internet use among first year university students? PsychNology Journal, 11(3), 235249.

Sheldon, K. M., Klinesmith, J., Houser-Marko, L., Osbaldiston, R., \& Gunz, A. (2007). Comparing IAT and TAT measures of power versus intimacy motivation. European Journal of Personality, 21, 263 280 .

Shoda, Y., Mischel, W., \& Peake, P. K. (1990). Predicting adolescent cognitive and self-regulatory competencies from preschool delay of gratification: Identifying diagnostic conditions. Developmental Psychology, 26, 978-986.
Tangney, J. P., Baumeister, R. F., \& Boone, A. L. (2004). High self-control predicts good adjustment, less pathology, better grades, and interpersonal success. Journal of Personality, 72, 271-322.

Vohs, K. D., \& Baumeister, R. F. (2004). Understanding self-regulation: An introduction. In R. F. Baumeister \& K. D. Vohs (Eds.), Handbook of Selfregulation. Research, theory, and applications (pp. 1-9). New York: Guilford.

Zimmerman, B. J. (2000). Attaining self-regulation: A social cognitive perspective. In M. Boekaerts, P. R. Pintrich, \& M. Zeidner (Eds.), Handbook of selfregulation (pp. 13-39). San Diego: Academic Press. Zumbo, B. D. (1999). A Handbook on the theory and methods of Differential Item Functioning (DIF). Logistic regression modeling as a unitary framework for binary and Likert-type (Ordinal) item scores. Ottawa ON: Directorate of Human Resources Research and Evaluation, Department of National Defense. 